\title{
SUPLEMENTAÇÃO DE EXTRATO DE LEVEDURA NA DIETA DE POEDEIRAS: QUALIDADE DE OVOS
}

\author{
SUPPLEMENTATION OF A YEAST EXTRACT PRODUCT IN LAYER DIETS: EGG QUALITY \\ Nunes, J.K. ${ }^{1 *}$, Maier, J.C. ${ }^{2 A}$, Rossi, P. ${ }^{3 A}$, Dallmann, P.R. ${ }^{4 A}$, Silveira, M.H.D. ${ }^{3 B}$, Anciuti, M.A. ${ }^{4 B}$, \\ Rutz, F. ${ }^{2 B}$ e Silva, J.G.C. da ${ }^{5}$
}

1PPGZ. FAEM. UFPEL. Pelotas, RS. Brasil. *julianaklug@yahoo.com.br

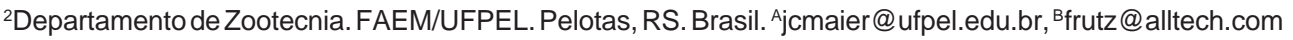
${ }^{3 A}$ rossi_patricia@yahoo.com.br, Bmartahds@gmail.com

${ }^{4}$ Conjunto Agrotécnico Visconde da Graça. UFPEL. Pelotas, RS. Brasil. Aprdallmann@hotmail.com, Banciuti@brturbo.com.br

${ }^{5}$ Departamento de Estatística. UFPEL. Pelotas, RS. Brasil. jgcs@ufpel.edu.br

\section{PalaVRas ChaVe ADICIONAIS}

Hy Line W36. Nucleotídeos. Nutrição.

\section{RESUMO}

Esta pesquisa teve por objetivo avaliar o efeito de extrato de levedura (NuPro®) no intervalo de 0 a $3 \%$ sobre a qualidade externa e interna dos ovos. Duzentas e quarenta poedeiras Hy Line W36 com 47 semanas de idade foram distribuídas em 60 gaiolas, perfazendo quatro aves por gaiola, e quatro níveis de extrato de levedura $(0,1,2$ e 3\%) foram assinalados às 60 gaiolas de modo a constituir 15 repetições por tratamento. Foram mensuradas as características: peso do ovo, gravidade específica, peso e espessura da casca, altura do albúmen, unidade Haugh e pesos da gema e do albúmen. Os valores observados dessas características foram submetidos às análises de variação e de regressão polinomial. O valor de $p<0,05$ foi estabelecido para a determinação de significância. A gravidade específica e o peso da casca dos ovos foram influenciados significativamente pelo extrato de levedura. A melhor gravidade específica dos ovos foi obtida com a inclusão de 1,4\% do extrato de levedura na dieta das poedeiras.

\section{SUMMARY}

This study aimed to evaluate levels $(0,1,2$ and $3 \%$ ) of yeast extract product (NuPro ${ }^{8}$ ) on internal and external quality of eggs. A total of $240 \mathrm{Hy}$ Line W36 layers (47 to 75 weeks of age) were allocated

Recibido: 22-4-08. Aceptado: 17-11-08.

\author{
AdDitionAl KEYWORDS \\ Hy Line W36. Nucleotides. Nutrition.
}

in 60 cages ( 4 birds per cage) and divided into 15 cages per treatment. Egg weight, specific gravity, shell weight and thickness, albumen height, Haugh units, and yolk and albumen weight were evaluated. Data were subjected to ANOVA and polynomial regression. $A p<0.05$ was required for statements of significance. Specific gravity and eggshell weight were statistically influenced by dietary yeast extract. Results indicated that addition of $1.4 \%$ NuPro ${ }^{\circ}$ resulted in better specific gravity.

\section{INTRODUÇÃO}

As exigências do mercado e a evolução da ciência avícola têm transformado a atividade de produção de aves e ovos em uma grande indústria de alimentos (Honma, 1992). Isso tem implicado grandes mudanças nos padrões de produção. Particularmente, são notórios os aumentos da pressão por parte dos produtores para tornar a produção mais eficiente, com menor custo e melhor desempenho dos animais, e da demanda dos consumidores que estão cada vez mais preocupados com a qualidade dos produtos, exigindo alimentos saudáveis, com ausência de antibióticos e resíduos (Sartory et al., 
2003). Visando atender às exigências do mercado, o enfoque das pesquisas tem sido a busca por alimentos alternativos que, ao serem suplementados às dietas, atuem melhorando a qualidade dos produtos sem afetar a eficiência alimentar.

Um deles é o extrato hidrolisado da levedura Saccharomyces cerevisiae cepa 1026, que é obtido após a extração da parede celular da levedura pelo processamento com enzimas proteolíticas. Este extrato de levedura, além de ter um alto conteúdo protéico, é rico em: a) inositol, componente das membranas celulares necessário para o funcionamento dos nervos, cérebro e músculos (D'Souza e Frio, 2007); b) glutamato, que é importante para o metabolismo ( $\mathrm{Wu}$, 1998; Garattini, 2000), c) nucleotídeos, que são nutrientes essenciais envolvidos no desenvolvimento do músculo esquelético, na função cardíaca (Grimble e Westwood, 2000), no aumento da resistência imunológica (Uavy, 1989; Quershi, 2002) e na melhoria da integridade intestinal e da flora microbiana do trato gastrointestinal com o desenvolvimento de microrganismos benéficos (Mateo et al., 2004; Uauy, et al. 1994; Bohorquez et al., 2007); e d) peptídeos, que promovem melhoria no desempenho dos animais (Maribo, 2000; Tibbets, 2000; Moughan, 2001)

Trabalho realizado por Silva et al.(2007) com a suplementação de 1, 2 e 3\% de extrato de levedura em dietas para poedeiras em pico de produção demonstraram resultados equivalentes ao do tratamento controle para peso do ovo, gravidade específica, cor da gema, altura do albúmen, unidade Haugh, pesos da gema e do albúmen e peso e espessura da casca dos ovos.

Outros autores (Panobianco et al., 1989; Butolo, 1991; Ozturk e Ozen, 1994; Maia et al., 2001) utilizaram a suplementação de níveis, que variaram de 0 a $28 \%$, da levedura S. cerevisiae, obtida por meio de centrifugação e desidratação após a fermentação do caldo de cana-de-açúcar, na dieta de poedeiras com idades que variaram de 18 a
53 semanas e registraram resultados não significativos para a característica peso do ovo.

Os percentuais de levedura utilizados na alimentação animal são superiores àqueles do extrato de levedura, possivelmente isso se deva à presença da parede celular espessa e rígida da levedura que a torna resistente à ação de enzimas digestivas (Galvez et al., 1990; Devresse, 2000), enquanto que o extrato de levedura apresenta altos níveis de proteína solúvel (Devresse, 2000).

A utilização do extrato de levedura vem sendo pesquisada em vários países, porém poucos são os trabalhos com poedeiras, principalmente após o pico de produção. Esta pesquisa teve como objetivo avaliar o efeito do extrato de levedura sobre a qualidade externa e interna dos ovos de poedeiras, no período de 47 a 75 semanas de idade.

\section{MATERIAL E MÉTODOS}

O experimento foi conduzido nas instalações avícolas do Conjunto Agrotécnico Visconde da Graça, pertencente à Universidade Federal de Pelotas, com período experimental de 196 dias.

Foram utilizadas 240 poedeiras da linhagem Hy Line W36 com idade inicial de 47 semanas. As aves foram distribuídas ao acaso em 60 gaiolas de um aviário do tipo dark house, sendo que cada unidade experimental foi constituída por uma gaiola com quatro poedeiras alojadas. Durante o período experimental, as poedeiras receberam água e ração à vontade e foram submetidas a um programa de luz de 17 horas diárias.

As dietas foram formuladas à base de milho e de farelo de soja, sendo utilizadas quatro dietas experimentais constituídas por ausência e suplementação do extrato de levedura (NuPro®) nos níveis de 1\%, 2\% e $3 \%$ (tabela I). Pela composição percentual das dietas (tabela I), observa-se que o extrato de levedura foi utilizado como um ingre-

Archivos de zootecnia vol. 59, núm. 227, p. 370. 
EXTRATO DE LEVEDURA NA DIETA DE POEDEIRAS: QUALIDADE DE OVOS

Tabela I. Composição percentual e constituintes das dietas experimentais. (Percentual composition of experimental diets).

\begin{tabular}{|c|c|c|c|c|}
\hline Ingredientes (\%) & $0 \%$ & $1 \%$ & $2 \%$ & $3 \%$ \\
\hline Milho & 63,82 & 63,44 & 63,06 & 62,76 \\
\hline Farelo de soja & 23,40 & 22,50 & 21,60 & 20,70 \\
\hline Farelo de arroz desengordurado e peletizado & 0,80 & 1,10 & 1,40 & 1,70 \\
\hline Farinha de ostra (36\%) & 8,40 & 8,50 & 8,60 & 8,60 \\
\hline Sal iodado & 0,36 & 0,32 & 0,26 & 0,24 \\
\hline Fosfato bicálcico & 0,22 & 0,14 & 0,08 & 0,00 \\
\hline Extrato de levedura $^{1}$ & 0,00 & 1,00 & 2,00 & 3,00 \\
\hline Suplemento mineral, vitamínico e aminoácidos² & 3,00 & 3,00 & 3,00 & 3,00 \\
\hline Total & 100,00 & 100,00 & 100,00 & 100,00 \\
\hline \multicolumn{5}{|l|}{ Constituintes } \\
\hline Energia metabolizável (kcal/kg) & 2720 & 2720 & 2720 & 2720 \\
\hline Proteína bruta (\%) & 16,03 & 16,12 & 16,20 & 16,30 \\
\hline Cálcio (\%) & 4,00 & 4,00 & 4,00 & 4,00 \\
\hline Fósforo total (\%) & 0,62 & 0,61 & 0,60 & 0,59 \\
\hline Fósforo disponível (\%) & 0,42 & 0,42 & 0,42 & 0,42 \\
\hline Sódio total (\%) & 0,18 & 0,18 & 0,16 & 0,18 \\
\hline Aminoácidos totais (\%) & 0,60 & 0,60 & 0,60 & 0,60 \\
\hline Aminoácidos digestíveis (\%) & 0,54 & 0,54 & 0,54 & 0,54 \\
\hline Metionina total (\%) & 0,32 & 0,32 & 0,32 & 0,32 \\
\hline Metionina + cistina total (\%) & 0,61 & 0,61 & 0,61 & 0,61 \\
\hline Lisina total $(\%)$ & 0,86 & 0,86 & 0,86 & 0,86 \\
\hline Colina sintética (mg/kg) & 73,00 & 70,00 & 70,00 & 70,00 \\
\hline Colina total (mg/kg) & 1055,80 & 1070,80 & 1085,80 & 1100,80 \\
\hline Ácido linoléico (\%) & 1,59 & 1,58 & 1,57 & 1,55 \\
\hline Gordura bruta (\%) & 2,71 & 2,59 & 2,66 & 2,64 \\
\hline Fibra bruta (\%) & 2,90 & 2,85 & 2,82 & 2,78 \\
\hline
\end{tabular}

Níveis de garantia por kg do produto: ${ }^{1}$ Suplemento protéico e energético vegetal (NuPro® produzido pela empresa Alltech Biotechnology): proteína bruta: 51,10\% e energia metabolizável: $2728 \mathrm{kcal} / \mathrm{kg} ;{ }^{2} \mathrm{Núcleo}$ postura da empresa Brastec: cálcio: 269 g; fósforo: 94 g; manganês: 2334 mg; zinco: 1667 mg; ferro: 2000 mg; cobre: 334 mg; iodo: 12 mg; selênio: 10,2 mg; vitamina A: 334000 Ul; vitamina $D_{3}$ : 67000 UI; vitamina E: $234 \mathrm{mg}$; vitamina K3: $50 \mathrm{mg}$; vitamina $B_{1}: 54 \mathrm{mg}$; vitamina $B_{2}: 147 \mathrm{mg}$; vitamina $B_{6}: 100 \mathrm{mg}$; vitamina $B_{12}: 400$ mcg; niacina: 867 mg; ácido fólico: 24 mg; ácido pantotênico: 334 mg e metionina: 34 g.

diente, logo os níveis de inclusão de milho, farelo de soja, farelo de arroz desengordurado, farinha de ostra, fosfato bicálcico e sal iodado variaram de acordo com os percentuais de inclusão do extrato de levedura, pois se buscava a valorização dos nutrientes, descritas pelo fabricante, deste composto (tabela II) e por esta razão as dietas formuladas foram isoenergéticas (2720 kcal EM/kg), isocálcicas (4,0\% Ca), isofosfóricas $(0,42 \% \mathrm{Pd})$ e isoaminoacídicas (0,60\%).

As quatro dietas foram assinaladas de modo completamente aleatório às 60 gaiolas de modo a constituir 15 repetições de cada tratamento. O extrato de levedura foi produzido a partir do processamento da levedura Saccharomyces cerevisiae cepa 1026 e seus constituintes são apresentados na tabela II.

Archivos de zootecnia vol. 59, núm. 227, p. 371. 
Tabela II. Constituintes do extrato de levedura. (Composition of yeast extract).

\begin{tabular}{lccc}
\hline Constituintes & \multicolumn{3}{c}{ Valores } \\
\hline Energia & \multicolumn{3}{c}{$2728 \mathrm{kcal} / \mathrm{kg}$} \\
Gordura bruta & $0,20 \%$ \\
Carboidratos totais & $22,20 \%$ \\
Fibra & $0,40 \%$ \\
Nutrientes digestíveis totais & $72,60 \%$ \\
Proteína bruta & & $51,10 \%$ \\
Ácidos nucléicos & totais & $5,40 \%$ \\
& & & \\
Aminoácidos & $\%$ & Aminoácidos & $\%$ \\
Lisina & 2,82 & Metionina & 0,76 \\
Alanina & 3,03 & Ornitina & 0,09 \\
Arginina & 1,94 & Fenilalanina & 1,93 \\
Ácido aspártico & 3,87 & Prolina & 2,18 \\
Cisteína & 0,53 & Serina & 2,00 \\
Ácido glutâmico & 5,27 & Taurina & 0,09 \\
Glicina & 2,00 & Treonina & 2,00 \\
Histidina & 1,00 & Tirosina & 1,54 \\
Isoleucina & 2,00 & Valina & 2,54 \\
Leucina & 3,72 & Triptofano & 0,51 \\
\hline
\end{tabular}

Fonte: Lyons, 2001.

Foram avaliadas as seguintes características referentes à qualidade externa e interna dos ovos: peso do ovo (g), gravidade específica $\left(\mathrm{g} / \mathrm{cm}^{3}\right)$, peso (g) e espessura $(\mathrm{mm})$ da casca, altura do albúmen $(\mathrm{mm})$, unidade Haugh e pesos da gema e do albúmen (g).

A coleta e o registro do número de ovos produzidos por unidade experimental foram realizados diariamente pela manhã. Para as avaliações das características de qualidade externa e interna dos ovos, a cada ciclo de 28 dias, procedeu-se a coleta de todos os ovos de cada unidade experimental que foram identificados e pesados, o que totalizou sete avaliações. Imediatamente após a coleta, foi realizada a determinação da gravidade específica. Para isso, foram preparadas soluções salinas com concentrações de cloreto de sódio que variaram de 1,062 até 1,102 com intervalo de 0,004 entre as soluções. Considerou-se como gravidade específica do ovo a concentração da solução na qual ele flutuou (Hamilton, 1982). Depois da avaliação da gravidade específica, cada ovo foi quebrado individualmente para as demais avaliações. A altura do albúmen foi realizada com uma régua específica (marca FHK) posicionada perpendicularmente à posição das chalazas. A gema foi separada do albúmem e pesada, enquanto que a casca, depois de lavada e seca por 24 horas em estufa de ventilação forçada a $60^{\circ} \mathrm{C}$, foi pesada e medida, na porção mediana, com o auxílio de um paquímetro digital (marca Starret). O peso do albúmen foi determinado por diferença e a unidade Haugh calculada pela fórmula:

$\mathrm{UH}=100 \times \log$ (altura do albúmen espesso $(\mathrm{mm}))+7,57-\left[1,7 \times\right.$ peso do ovo $\left.(\mathrm{g})^{0,37}\right]$ ) (Willians, 1992).

As variáveis respostas foram submetidas à análise de variação, seguida da decomposição da variação entre os tratamentos em componentes polinomiais e do ajustamento de curva de resposta de grau apropriado, não superior a dois. Foi adotado o nível de significância de 5\% nos testes de hipóteses efetuados.

Foi verificada variação significativa $(\mathrm{p}<0,05)$ do peso corporal inicial (PCI) das poedeiras entre os tratamentos. Como foi revelada relação linear significativa entre peso do ovo e PCI, as análises dessa variável resposta foram procedidas com ajustamento para o PCI. Entretanto, esse ajustamento não foi efetuado para as demais variáveis, que não revelaram relação linear com o PCI.

As análises estatísticas, para o peso do ovo, foram baseadas no modelo estatístico com a seguinte equação:

$$
Y_{i j}=\mu+\beta p_{i j}+t_{i}+e_{i j},
$$

onde:

$Y_{i j}=$ observação média na unidade experimental (gaiola com quatro aves) correspondente à jésima repetição $(j=1,2, \ldots, 15)$ do i-ésimo tratamento $(i=1,2,3,4)$;

Archivos de zootecnia vol. 59, núm. 227, p. 372. 
$\mu=$ média geral esperada;

$\beta=$ coeficiente de regressão da variável resposta $\mathrm{Y}$ em relação à covariável $\mathrm{PCl}$;

$\mathrm{p}_{\mathrm{ij}}=$ valor da covariável na unidade experimental ij; $\mathrm{t}=$ efeito diferencial esperado do tratamento $\mathrm{i}$;

$\mathrm{e}_{\mathrm{ij}}=$ erro aleatório (efeito conjunto das características estranhas) correspondente à observação média na gaiola referente a j-ésima repetição do i-ésimo tratamento.

A equação do modelo estatístico adotado para cada uma das demais variáveis respostas foi a seguinte:

$$
Y_{i j}=\mu+t_{i}+e_{i j}
$$

\section{RESULTADOSEDISCUSSÃO}

Os resultados das análises estatísticas das variáveis que expressam qualidade externa e interna dos ovos estudadas estão apresentados na tabela III.

Verificou-se que o peso do ovo não foi afetado significativamente pelo extrato de levedura ( $p=0$,1769) (tabela III). Semelhantemente ao observado na presente pesqui- sa, Silva et al.(2007) também não verificaram variação significativa para o peso do ovo entre os tratamentos que continham 1,2 ou $3 \%$ do mesmo extrato de levedura na dieta basal de poedeiras, no período de 26 a 42 semanas de idade. Outros autores (Panobianco et al., 1989; Butolo, 1991; Ozturk e Ozen, 1994; Maia et al., 2001) também não constataram alteração significativa no peso do ovo de poedeiras alimentadas com níveis, da levedura $S$. cerevisiae, variando entre 0 e 28\%. Entretanto, Botelho et al. (1998) verificaram efeito quadrático significativo para a inclusão da levedura $S$. cerevisiae sobre o peso do ovo de poedeiras em pico de produção, sendo 2,5\% o nível indicado para a obtenção de ovos mais pesados. No período de 16 a 34 semanas de idade de poedeiras, Ayanwale et al. (2006) observaram que com a suplementação da levedura S. cerevisiae, nos níveis de 0,$25 ; 0,50 ; 0,75$ e $1 \%$, na dieta o peso do ovo produzido pelas aves alimentadas com $0,75 \%$ foi superior. Em um experimento realizado com a suplementação de níveis de 3 a 15\% da

Tabela III. Efeito do extrato de levedura sobre características que expressam qualidade externa e qualidade interna do ovo, no período experimental. (Effect of yeast extract on external and internal eggs traits during the experimental period).

\begin{tabular}{|c|c|c|c|c|c|c|c|c|c|}
\hline \multirow{2}{*}{ Tratamento } & \multicolumn{9}{|c|}{ Característica $^{1}$} \\
\hline & $\begin{array}{c}\text { CR } \\
\text { g/ave/dia }\end{array}$ & $\begin{array}{c}\mathrm{PO} \\
\mathrm{g}\end{array}$ & $\begin{array}{c}\mathrm{GE} \\
\mathrm{g} / \mathrm{cm}^{3}\end{array}$ & $\begin{array}{c}\mathrm{PC} \\
\mathrm{g}\end{array}$ & $\begin{array}{l}\mathrm{EC} \\
\mathrm{mm}\end{array}$ & $\begin{array}{l}\text { A A } \\
\text { mm }\end{array}$ & $\mathrm{UH}$ & $\begin{array}{c}P G \\
g\end{array}$ & $\begin{array}{l}\text { PA } \\
\text { g }\end{array}$ \\
\hline$\%$ & 11 & 59,20 & 1, & 5,25 & 0,4 & 9,05 & 94,60 & 15,64 & 39 \\
\hline 2) & 113 & 59,20 & 1,085 & 5,20 & 0,40 & 8,93 & 94,00 & 15,54 & 39,30 \\
\hline $2 \%$ NuPro ${ }^{\circledR}$ & 113 & 60,40 & 1,086 & 5,48 & 0,40 & 9,00 & 94,27 & 15,98 & 40,37 \\
\hline 3\% NuPro® & 113 & 59,60 & 1,084 & 5,20 & 0,40 & 9,10 & 94,87 & 15,74 & 39,78 \\
\hline Média & 113 & 59,6 & 1,085 & 5,28 & 0,40 & 9,02 & 94,44 & 15,73 & 39,81 \\
\hline $\mathrm{P}^{2}$ : efeito do NuPro® & 0,1691 & 0,1769 & 0,0129 & 0,0061 & 0,2494 & 0,7289 & 0,7361 & 0,2808 & 0,4890 \\
\hline $\mathrm{CV} \%^{3}$ & 0,70 & 2,91 & 0,23 & 6,65 & 9,12 & 8,31 & 4,08 & 5,49 & 8,73 \\
\hline Curva ajustada ${ }^{4}$ & Const. & Const. & Quadr. ${ }^{5}$ & Const. & Const. & Const. & Const. & Const. & Const. \\
\hline
\end{tabular}

${ }^{1} \mathrm{CR}$ : consumo de ração, PO: peso do ovo, GE: gravidade específica, PC: peso da casca, EC: espessura da casca, AA: altura do albúmen, UH: unidade Haugh, PG: peso da gema, PA: peso do albúmen. ${ }^{2} \mathrm{P}$ : probabilidade de declarar significativo efeito do extrato de levedura inexistente. ${ }^{3} \mathrm{CV} \%$ : coeficiente

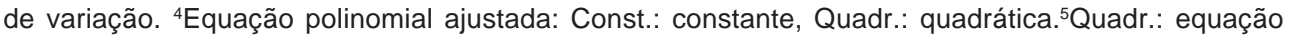
polinomial quadrática: $\mathrm{GE}=1,084+1,58 \times-0,55 \mathrm{x}^{2} ; \mathrm{r}^{2}=0,57$. 
levedura S. cerevisiae na dieta de codornas, no período de 14 a 23 semanas de idade, Sucupira et al. (2007) observaram que o peso do ovo aumentou linearmente com o acréscimo da levedura na dieta.

Neste estudo, os ovos produzidos pelas aves que receberam a suplementação do extrato de levedura apresentaram peso equivalente ou mais elevado, isso pode ser atribuído à presença dos peptídeos neste hidrolisado protéico, pois estes, além de apresentarem maior digestibilidade (Grimble et al., 1986), atuam disponibilizando aminoácidos para a síntese protéica (Gardner, 1998). Assim como os peptídeos, os nucleotídeos também estão envolvidos no metabolismo de carboidratos, proteínas e gorduras (Lerner e Shamir, 2000) o que pode resultar em maior peso do ovo (Leeson, 1996; Murakami e Furlan, 2002; Pinto et al., 2002; Freitas et al., 2005).

Os resultados revelam efeito significativo $(p=0,0129)$ do extrato de levedura sobre a gravidade específica, com variação de resposta polinomial quadrática $(\mathrm{GE}=1,084$ $\left.+1,58 x-0,55 x^{2} ; r^{2}=0,57\right)$ (tabela III). O máximo desta equação é alcançado para $x=1,4 \%$, o que indica que a melhor gravidade específica dos ovos se situa entre os níveis de 1 e $2 \%$ do extrato de levedura.

A gravidade específica está diretamente relacionada com a resistência da casca do ovo à quebra (Abdallah et al., 1993). Neste experimento, a qualidade da casca dos ovos representada pela gravidade específica foi adequada, pois ficou acima de 1,080 (figura 1), que segundo Balander et al. (1997) é o valor mínimo para que os ovos comerciais resistam ao transporte e ao processamento.

Ao contrário do que foi observado neste experimento, Silva et al. (2007), utilizando os tratamentos controle e níveis 1, 2 e 3\% do extrato de levedura NuPro ${ }^{\circledR}$, no período de 26 a 42 semanas de idade de poedeiras, concluíram que a gravidade específica não foi afetada pela adição do extrato de levedura na matriz nutricional das dietas.

A gravidade específica dos ovos apresenta relação direta com o percentual de casca (Olsson, 1934 citado por Sechinato,

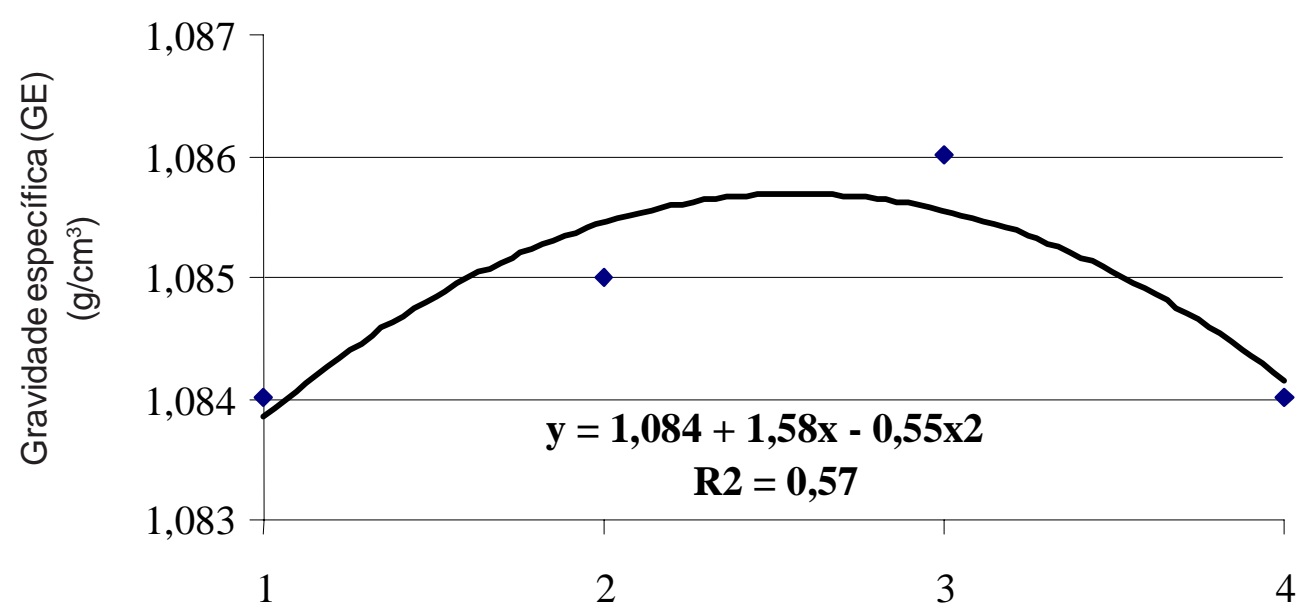

Níveis do extrato de levedura (\%)

Figura 1. Gravidade específica dos ovos produzidos pelas poedeiras alimentadas com extrato de levedura, no período experimental. (Specific gravity of eggs laid by layers fed yeast extract during the experimental period).

Archivos de zootecnia vol. 59, núm. 227, p. 374. 
2003). Esta observação foi confirmada nesta pesquisa, pois se observou efeito significativo $(\mathrm{p}<0,05)$ do extrato de levedura tanto para a gravidade específica como para o peso da casca com variação de resposta polinomial constante.

Resultado semelhante foi observado por Sucupira et al. (2007) que demonstraram que os níveis de 3, 6, 9, 12 e 15\% de suplementação da levedura $S$. cerevisiae tiveram efeito quadrático sobre a percentagem de casca dos ovos de codornas no período de 14 a 23 semanas de idade. Por outro lado, Silva et al. (2007) ao utilizarem os tratamentos com $0,1,2$ e $3 \%$ do mesmo extrato de levedura na dieta basal de poedeiras Hisex Brown, em pico de produção, não verificaram variação significativa entre os tratamentos para esta característica.

Possivelmente os resultados obtidos neste estudo para as variáveis gravidade específica e peso da casca dos ovos tiveram interferência da composição do extrato de levedura na digestibilidade e absorção de minerais.

A adição do extrato de levedura nos níveis considerados não promoveu efeito significativo sobre a espessura da casca

\section{BIBLIOGRAFIA}

Abdallah, A.G., Harms, R.H. and El-Husseiny, O. 1993. Various methods of measuring shell quality in relation to percentage of cracked eggs. Poultry Sci., 72: 2038-2043.

Ayanwale, B.A., Kpe, M. and Ayanwale, V.A. 2006. The effect of supplementing Saccharomyces cerevisiae in the diets on egg laying and egg quality characteristics of pullets. Poultry Sci., 5: 759-763.

Balander, R.J., Flegal, C.J. and Stefton, T. 1997. The effects of SSF on egg production and egg specific gravity in laying hens. Poultry Sci., 76: 3.

Bohorquez, D.V., Santos Jr., A.A., Nanney, R.L. and Ferket, P.R. 2007. Nutritional assessment of yeast extract (NuPro $\left.{ }^{\circledR}\right)$ in male turkey poults. In: Nutritional Biotechnology in the Feed and Food Industries, 23. Lexington, KY, USA. Abstracts
( $p=0,2494)$, a altura do albúmen ( $p=0,7289)$, a unidade Haugh $(\mathrm{p}=0,7361)$, o peso da gema $(\mathrm{p}=0,2808)$ e o peso do albúmen $(\mathrm{p}=$ 0,4898 ) ao final do período experimental (tabela III). Estes resultados corroboram com os de Silva et al. (2007). A ausência de variação significativa entre os tratamentos para peso da gema e do albúmen também estão de acordo com os resultados observados por Sucupira et al. (2007) que incluíram níveis variando de 3 a $15 \%$ da levedura $S$. cerevisiae na dieta basal de codornas, no período de 14 a 23 semanas de idade. $\mathrm{Na}$ avaliação da suplementação da levedura $S$. Cerevisiae em cinco níveis $(0 ; 0,25 ; 0,50$; 0,75 e 1\%), Ayanwale et al. (2006) observaram que o peso da gema do ovo produzido por poedeiras, no período de 16 a 34 semanas de idade, foi significativo, sendo que com a suplementação de $0,75 \%$ da levedura o peso da gema foi superior.

\section{CONCLUSÃO}

O fornecimento de $1,4 \%$ do extrato de levedura na dieta de poedeiras, de 47 a 75 semanas de idade, resulta em melhor gravidade específica dos ovos.

of posters presented at Alltech's $23^{\text {rd }}$ Annual Symposium (Suppl. 1). Lexington, KY. USA. pp. 20.

Botelho, F.G.A., Serafini, F.V. e Butolo, E.A.F. 1998. Estudo do desempenho de galinhas poedeiras alimentadas com levedura de canade-açúcar (Saccharomyces cerevisiae). Em: Reunião Anual da Sociedade Brasileira de Zootecnia, 35. Botucatu. Anais... SBZ. Botucatu. pp. 324-326.

Butolo, J.E. 1991. Valor nutricional da levedura. Em: Seminário de Produção e Comercialização de Levedura, 2. Piracicba. Anais... Cooperativa de Produtores de Cana, Açúcar e Álcool do Estado de São Paulo. Piracicaba. pp. 1-6.

D'Souza, D. and Frio, A. 2007. Bridging the postweaning piglet growth gap: the NuPro ${ }^{\circledR}$ experience in the Asia Pacific region. In: Nutritional

Archivos de zootecnia vol. 59, núm. 227, p. 375. 


\section{NUNES, MAIER, ROSSI, DALLMANN, SILVEIRA, ANCIUTI, RUTZE SILVA}

Biotechnology in the Feed and Food Industries, 23. Lexington, KY, USA. Proceedings of Alltech's $23^{\text {rd }}$ Annual Symposium. Nottinghan University Press. Nottinghan. pp. 41-48.

Devresse, B. 2000. Nucleotides: a key nutrient for the immune system of shrimp? Feed Mix, 8: 2022.

Freitas, A.C., Fuentes, M.F.F., Freitas, E.R., Sucupira, F.S. e Oliveira, B.C.M. de. 2005. Efeito dos níveis de proteína bruta e de energia metabolizável na dieta sobre o desempenho de codornas de postura. Rev. Soc. Bras. Zootecn., 34: 838-846.

Galvez, A., Ramírez, M.J. and Garcia-Garibay, M. 1990. Chemical composition of a mixture of single cell protein obtained from Kluyveromyces fragilis and whey proteins. Arch. Latinoam. Nutr., 40: 252-262.

Garattini, S. 2000. Glutamic acid, twenty years later. J. Nutr., 130: 901-909.

Gardner, M.L.G. 1998. Transmucosal passage of intact peptides. In: Peptides in mammalian protein metabolism. Portland Press. London. pp. 11.

Grimble, G.K., Keohane, P.P., Higgins, B.E., Keohane, P.P., Grimble, G.K., Brown, B. and Spiller, R.C. 1986. Influence of protein composition and hydrolysis method on intestinal absorption of protein in man. Gut, 26: 907-913.

Grimble, G.K. and Westwood, M.R. 2000. Nucleotides. In: Nutrition and immunology. Principles and practice. Humana Press. Totowa, NJ. USA. pp. 135-144.

Hamilton, R.M.G. 1982. Methodos and factors that affect the measurement of egg shell quality. Poultry Sci., 61: 2022-2039.

Honma, N.H. 1992. Efeito dos níveis nutricionais de cálcio sobre a capacidade reprodutiva e integridade dos ossos de galos reprodutores de corte. Dissertação (Mestrado em Zootecnia). Universidade Federal de Viçosa. Viçosa. $63 \mathrm{pp}$.

Leeson, S. 1996. Programas de alimentación para ponedoras y broilers. En: XII Curso de Especialización FEDNA. Madrid. España. pp. 201-216.

Lerner, A. and Shamir, R. 2000. Nucleotides in infant nutrition: a must or an option. IMA J., 2: 772-774.

Lyons, P. 2001. A time for answers: solutions for the 2001 feed industry. In: Nutritional Biotechnology in the feed and food industries, 17.
Nottinghan. Proceedings of Alltech's $17^{\text {th }}$ Annual Symposium. Nottinghan University Press. Nottinghan. pp. 1-23.

Maia, G.A.R., Fonseca, J.B., Soares, R.T.R.N., Silva, M.A. e Souza, C.L.M. 2001. Desempenho de poedeiras comerciais alimentadas com levedura seca (Saccharomyces cerevisiae) de cana-de-açúcar. Rev. Bras. Ciência Avíc., 3: 163-171.

Maribo, H. 2000. Commercial products for weaners. NuProTM2000 as an alternative protein source for weaners. In: The National Committee for Pig Production, Danish Bacon and Meat Council. Danske Slagterier. Denmark. Report n. 256.

Mateo, C.D., Peters, D.N., Dave, R.I. and Stein, H.H. 2004. Effects of dietary nucleosides on intestinal microbial activity and performance of newly weaned pigs. In: Nutritional Biotechnology in the Feed and Food Industries, 20. Lexington, KY, USA. Abstracts of posters presented at Alltech's $20^{\text {th }}$ Annual Symposium (Suppl. 1). Lexington, KY. USA. pp. 55.

Moughan, P. 2001. Dietary protein-from amino acid supply to bioactive peptides. In: Nutritional Biotechnology in the Feed and Food Industries, 17. Nottinghan. Proceedings of Alltech's 17th Annual Symposium. Nottinghan University Press. Nottinghan. pp. 33-47.

Murakami, A.E. e Furlan, A.C. 2002. Pesquisas na nutrição e alimentação de codornas em postura no Brasil. Em: Simpósio Internacional de Coturnicultura. Lavras. Anais... UFLA. Lavras. pp. 113-120.

Ozturk, E. and Ozen, N. 1994. The utilization of dried wine yeast residue in layers and broiler diets. Turk. J. Vet. Anim. Sci., 18: 251-257.

Panobianco, M.A., Ariki, J. e Junqueira, O.M. 1989. Utilização da levedura seca (Saccharomyces cerevisae) de álcool da cana-de-açúcar em dietas poedeiras. Rev. Soc. Bras. Zootecn., 18: 13-20.

Pinto, R., Ferreira, A.S., Albino, L.F.T., Gomes, P.C. e Vargas, J.G. de. 2002. Níveis de proteína e energia para codornas japonesas em postura. Rev. Soc. Bras. Zootecn., 31: 1761-1770.

Quershi, M.A. 2002. Differencial expression of inducible nitric oxide synthase is associated with differencial toll-like receptor - 4 expression in chicken macrophages from different genetic backgrounds. Vet. Immunol. Immunopathol.,

Archivos de zootecnia vol. 59, núm. 227, p. 376. 


\section{EXTRATO DE LEVEDURA NA DIETA DE POEDEIRAS: QUALIDADE DE OVOS}

84: 191-207.

Sartory, J.R., Pereira, K.A., Gonçalves, J.C., Cruz, V.C., Pezzato, D.F. e Pinheiro, D.F. 2003. Enzimas e simbiótico para frangos de corte nos sistemas convencional e alternativo. 2 . Rendimento de carcaça, partes e gordura abdominal. In: Conferência APINCO de Ciência e Tecnologia Avícolas, Suppl.5. Campinas. Anais ... FACTA. Campinas. pp. 10.

Sechinato, A.S. da. 2003. Efeito da suplementação dietética com microminerais orgânicos na produção e qualidade de ovos de galinhas poedeiras. Tese (dissertação). Faculdade de Veterinária e Zootecnia. Universidade de São Paulo. São Paulo. 59 pp.

Silva, R.A.G., Gentilini, F.P., Nunes, P.M., Anciuti, M.A. and Rutz, F. 2007. Effects of NuPro ${ }^{\circledR}$ on egg production and egg quality in layers from 26 to 42 weeks of age. In: Nutritional Biotechnology in the Feed and Food Industries, 23. Lexington. Abstracts of posters presented at Alltech's $23^{\text {rd }}$ Annual Symposium (Suppl. 1). Lexington, KY. USA. pp. 27.
Sucupira, F.S., Fuentes, M.F.F., Freitas, E.R. e Braz, N.M. 2007. Alimentação de codornas de postura com rações contendo levedura de canade-açúcar. Ciência Rural, 37: 528-532.

Tibbets, G.W. 2000. Biopeptides in post weaning diets for pigs: results to date. In: Nutritional Biotechnology in the Feed and Food Industries, 16. Nottinghan. Proceedings of Alltech's $16^{\text {th }}$ Annual Symposium. Nottinghan University Press. Nottinghan. pp. 347-368.

Uauy, R., Quan, R. and Gil, A. 1994. Role of nucleotides in intestinal development and repair: implications for infant nutrition. J. Nutr., 124: 1436-1441.

Uavy, R. 1989. Dietary nucleotides and requirements in early life. In: Lebethal, E. Textbook of gastroenterology and nutrition in infancy. Raven Press, Ltda. New York. pp. 265-280.

Willians, K.C. 1992. Some factors affecting albumen quality with particular reference to Haugh unit score. World Poultry Sci. J., 48: 4-16.

Wu, G. 1998. Intestinal mucosal amino acid catabolism. J. Nutr., 128: 1249-1252.

Archivos de zootecnia vol. 59, núm. 227, p. 377. 